\title{
Expression of 11 $\beta$-hydroxysteroid dehydrogenase enzymes in human osteosarcoma: potential role in pathogenesis and as targets for treatments
}

\author{
Pushpa Patel, Rowan Hardy, Vaiyapuri Sumathi ${ }^{1}$, Gillian Bartle ${ }^{1}$, \\ Lars-Gunnar Kindblom ${ }^{1}$, Robert Grimer ${ }^{2}$, Iwona Bujalska, Paul M Stewart, \\ Elizabeth Rabbitt, Neil $J$ L Gittoes and Mark S Cooper
}

\author{
School of Clinical and Experimental Medicine, Institute of Biomedical Research, The University of Birmingham, \\ Birmingham B15 2TT, UK \\ ${ }^{1}$ Department of Musculoskeletal Pathology, Royal Orthopaedic Hospital NHS Foundation Trust, Queen Elizabeth Hospital, \\ Birmingham B15 2TT, UK \\ ${ }^{2}$ Oncology Department, Royal Orthopaedic Hospital NHS Foundation Trust, Birmingham B31 2AP, UK \\ (Correspondence should be addressed to M S Cooper at Centre for Endocrinology, Diabetes and Metabolism, Queen Elizabeth \\ Hospital, University of Birmingham, Edgbaston, Birmingham B15 2TH, UK; Email: m.s.cooper@bham.ac.uk)
}

\begin{abstract}
Osteosarcoma (OS) is a primary malignant tumour of bone occurring predominantly in children and young adults. Despite chemotherapy, relapse is common and mortality remains high. Nontransformed osteoblasts are highly sensitive to glucocorticoids, which reduce proliferation and induce apoptosis. Previously, we observed that OS cells, but not normal osteoblasts, express $11 \beta$-hydroxysteroid dehydrogenase type 2 (11 $\beta$-HSD2). This enzyme inactivates cortisol (active) to cortisone (inactive) and expression of $11 \beta$-HSD2 renders OS cells resistant to glucocorticoids. By contrast, the related enzyme 11 $\beta$-HSD1 converts cortisone to cortisol and reduces OS cell proliferation in vitro. Some synthetic glucocorticoids (e.g. dehydrodexamethasone (DHD), inactive counterpart of dexamethasone (DEX)) have been reported to be activated by $11 \beta-\mathrm{HSD} 2$. We therefore investigated expression and enzymatic activity of $11 \beta$-HSD isozymes in human OS tissue, determined whether $11 \beta-H S D$ expression has prognostic value in the response to therapy, and evaluated the potential use of synthetic glucocorticoids to selectively target OS cells. OS samples expressed both $11 \beta-$ HSD1 and $11 \beta$-HSD2. $11 \beta-$ HSD1 expression in pretreatment biopsy specimens positively correlated with primary tumour size. Expression and activity of $11 \beta$-HSD1 in post-treatment biopsies were unrelated to the degree of tumour necrosis following chemotherapy. However, high $11 \beta-H S D 2$ expression in post-treatment biopsies correlated with a poor response to therapy. OS cells that expressed $11 \beta$-HSD2 inactivated endogenous glucocorticoids; but these cells were also able to generate DEX from DHD. These results suggest that $O S$ treatment response is related to $11 \beta$-HSD2 enzyme expression. Furthermore, OS cells expressing this enzyme could be targeted by treatment with synthetic glucocorticoids that are selectively reactivated by the enzyme.

Endocrine-Related Cancer (2012) 19 589-598
\end{abstract}

\section{Introduction}

Osteosarcoma (OS) is the most common primary malignant tumour of bone occurring in children and adolescents (Wafa \& Grimer 2006). Surgical resection alone is associated with a survival rate of $\sim 11 \%$ due to the presence of systemic micrometastases at presentation. However, the introduction of systemic chemotherapy regimes followed by excision of the primary tumour has increased survival rates between 60 and $80 \%$ in patients without detected metastases at diagnosis (Raymond et al. 2002). Most OSs are high grade and there are few morphological markers relating to long-term survival. Patients with metastases at presentation have a very poor outlook. For patients 
without clinically evident metastasis, the most important prognostic factor is the response of the primary tumour to chemotherapy. The finding of $>90 \%$ postchemotherapy necrosis in the primary tumour is associated with a good prognosis (Marina et al. 2004, Wafa \& Grimer 2006). Conversely, <90\% necrosis is associated with a high probability of systemic relapse. Weaker prognostic factors include the size of the primary tumour and the level of serum alkaline phosphatase at diagnosis (Marina et al. 2004, Bramer et al. 2005).

OSs arise from cells of osteoblast lineage. Normal osteoblasts are highly sensitive to glucocorticoids, which have anti-proliferative, pro-differentiative and pro-apoptotic actions on these cells (Cooper 2004, O'Brien et al. 2004). The detrimental effects of therapeutic glucocorticoids are frequently observed in clinical practice and are manifest through increased risk of fracture/osteoporosis and osteonecrosis. In vitro experiments indicate that OS cells and cell-lines retain sensitivity to glucocorticoids (Kudawara et al. 2001). This suggests that OS in vivo could be sensitive (or sensitised) to glucocorticoids. At a cellular level, glucocorticoids are metabolised by

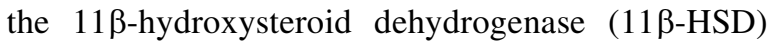
enzymes (Tomlinson et al. 2004, Cooper \& Stewart 2009). These intracellular enzymes interconvert hormonally active glucocorticoids with their inactive forms. The 11ß-HSD1 enzyme metabolises endogenous glucocorticoids, cortisone and cortisol, in a bidirectional manner, whereas $11 \beta-H S D 2$ is a unidirectional inactivator of endogenous glucocorticoids. We have previously demonstrated that OS cell lines express the 11 $\beta$-HSD2 enzyme (Bland et al. 1999, Eyre et al. 2001). This is in contrast to normal osteoblasts that express the $11 \beta$-HSD1 enzyme (Cooper et al. 2000, 2001, 2002). Expression of $11 \beta$-HSD2 is also seen in pituitary tumours and this expression is related to prognosis (Rabbitt et al. 2003). This raises the possibility that differences in glucocorticoid metabolising enzyme expression, and in particular 11ß-HSD2, could be relevant to OS prognosis or response to treatment.

Although $11 \beta$-HSD2 activity is unidirectional for endogenous glucocorticoids, several studies have demonstrated that the substitution of a fluoride molecule at the $9 \alpha$ position of the glucocorticoid structure (as seen in dexamethasone (DEX)) dramatically affects the way the enzyme metabolises these steroids (Diederich et al. 2002). $9 \alpha$-Fluorinated steroids are less effectively oxidised (inactivated) but in addition their inactive counterparts can be reduced (converted to their active form) by the $11 \beta-H S D 2$ enzyme. As such, it has been shown that $11 \beta$-HSD2 can efficiently convert dehydrodexamethasone (DHD; the inactive oxidised counterpart of DEX) and DEX in a bidirectional manner.

The aims of this study are to investigate the expression and enzymatic activity of the 11ß-HSD isozymes in human OS tissue before and after chemotherapy, to determine whether $11 \beta$-HSD expression has prognostic value in terms of response to therapy, and to evaluate the potential use of synthetic glucocorticoids in selectively targeting OS cells in patients who have responded poorly to chemotherapy.

\section{Materials and methods}

\section{Patients}

OS biopsy and post-treatment resection specimens were obtained from the Department of Musculoskeletal Pathology at the Royal Orthopaedic Hospital. All subjects gave informed consent and the study was approved by the Warwickshire Research Ethics Committee. Histological preparations of tissue samples were identical to those used as part of the departmental clinical service. Patient diagnoses were based on assessment by a consultant pathologist in collaboration with the Orthopaedic Oncology Multidisciplinary Team. Specifically, all biopsy samples and resection specimen were formalin-fixed and decalcified in 5\% nitric acid. Sections were stained with haematoxylin and eosin and examined microscopically. Diagnosis was based on the presence of matrix (osteoid/cartilage) producing frankly malignant sarcomatous stroma. Tumours with prominent osteoid were labelled as osteoblastic variant of OS. Tumours with more than $30 \%$ cartilaginous component were labelled as chondroblastic OS. To assess tumour size and percentage necrosis, all resection specimens were opened with a bandsaw and a slice through the entire bone with the tumour was taken. The slice was photographed and mapped. Blocks were submitted for histological evaluation. The effect of chemotherapy was assessed by the proportion of viable and necrotic areas and recorded in terms of the percentage of tumour necrosis. Tumour volume was estimated by multiplying tumour linear dimensions to give a volume in cubic centimetre. Serum alkaline phosphatase levels were recorded at the time of diagnosis and subsequently as a measure of treatment response. Patients were treated with chemotherapy regimens containing methotrexate, doxorubicin and cisplatin chemotherapy with or without ifosfamide and etoposide. 


\section{Immunohistochemistry}

Using the Labeled Streptavidin Biotin (LSAB)+ System-HRP technique (Dako, Ely, UK), immunohistochemistry was performed on formalin-fixed paraffinembedded human OS biopsy and post-chemotherapy OS specimens. Positive control sections included normal human liver for $11 \beta$-HSD1 and normal human kidney for $11 \beta$-HSD2. All tissue sections were prepared at the Department of Musculoskeletal Pathology (Royal Orthopaedic Hospital NHS Foundation Trust). Tissue sections were placed in a $60{ }^{\circ} \mathrm{C}$ heat block for $1 \mathrm{~h}$ before dewaxing in xylene and rehydration. The activity of endogenous peroxidase was blocked by $1 \%$ hydrogen peroxide for $10 \mathrm{~min}$. Antigen retrieval was achieved using $1 \times \mathrm{EDTA} / \mathrm{NaOH}$ buffer ( $\mathrm{pH} 8$ ) overnight for $16 \mathrm{~h}$. Sections were rinsed in warm water followed by cold water, then placed into a Sequenza immunostaining chamber and rinsed in tris-buffered saline (TBS) for $5 \mathrm{~min}$. Endogenous biotin was blocked using a biotin-blocking buffer (Dako). Sections were incubated with primary antibody

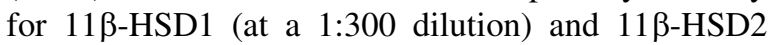
(1:300) (both from Binding Site, Birmingham, UK) in TBS for $1 \mathrm{~h}$ at room temperature. Sections were rinsed in TBS for $5 \mathrm{~min}$. Immunodetection was enhanced using the LSAB + System-HRP technique, where sections were incubated for $30 \mathrm{~min}$ with a biotinylated link solution for $30 \mathrm{~min}$, followed by TBS rinse for $5 \mathrm{~min}$ and another $30 \mathrm{~min}$ incubation with streptavidin peroxidase. Sections are incubated with 3,3-diaminobenzidine substrate-chromogen for $5 \mathrm{~min}$, followed by counterstaining of sections with Mayer's haematoxylin. Enzyme expression was assessed semiquantitatively in a blinded fashion on a scale of 0 to 4 , where 0 , indicated no expression; 1 , low expression; 2, medium expression; 3 , high expression and 4 , very high expression.

\section{Enzyme activity assay}

Enzyme activity assays were performed as previously reported (Hardy et al. 2008). Fresh tissue was collected from post-chemotherapy OS surgical resection specimens. Tissue samples were cut into $3-5 \mathrm{~mm}$ thick pieces and washed twice with sterile PBS. Tissue samples were treated with $100 \mathrm{nM}$ cortisone or $100 \mathrm{nM}$ cortisol in $500 \mu \mathrm{l} \mathrm{DMEM} / \mathrm{Ham}$ 's F12 (PAA Laboratories, Yeovil, UK) at $37^{\circ} \mathrm{C}$ for $24 \mathrm{~h}$ along with the respective tritiated tracer for each steroid. Tissue was removed and weighed after $24 \mathrm{~h}$, steroids were extracted from the media using dichloromethane and then separated by thin layer chromatography (TLC) using chloroform/ethanol (92:8). Steroid conversion was measured on the Bioscan 3000 image analyser (Lablogic, Sheffield, UK). Enzyme activity was expressed as picomole per gram of tissue per hour. Experiments were carried out in triplicate.

\section{RNA extraction, RT and real-time PCR}

RNA was extracted from OS tissue using the Trireagent extraction method (Sigma). RNA was further cleaned using a Qiagen RNAeasy kit. One microgram of total RNA was reverse transcribed using a RT kit (Applied Biosystems, Warrington, UK). 11ßHSD1, $11 \beta \mathrm{HSD} 2$ and alkaline phosphatase mRNA expression levels were quantified by real-time PCR using the ABI 7500 sequence detection system (Perkin-Elmer Applied Biosystems, Warrington, UK). Primer and probes for each gene including the housekeeping gene for 18S rRNA were purchased from Assay-on-Demand (Applied Biosystems). Reactions were run on MicroAmp Optical 96-Well plates, with $10 \mu$ reactions containing Taqman PCR master mix (Applied Biosytems) as per the manufacturer's instructions.

\section{Metabolism of synthetic glucocorticoids by 11 $\beta$-HSD enzymes}

Tritiated DHD ([3 $\mathrm{H}]$ DHD) was synthesised from tritiated DEX $\left(\left[{ }^{3} \mathrm{H}\right]\right.$ DEX (PerkinElmer, Warrington, UK)) using an in house method based on the $11 \beta$-HSD2 activity of human placenta (Cooper et al. 2000). Fifty microlitres placental homogenate were incubated with $20 \mu \mathrm{l}$ of $\left[{ }^{3} \mathrm{H}\right] \mathrm{DEX}, 50 \mu \mathrm{l} 0.1 \mathrm{M}$ potassium phosphate buffer (pH 7.6) and $380 \mu 110 \mu \mathrm{M}$ NAD at $37^{\circ} \mathrm{C}$ for $24 \mathrm{~h}$. Steroids were separated by TLC as previously described. Using the Bioscan imager and unlabelled DHD and DEX standards (observed on the basis of their intrinsic autofluoresence using a u.v. imager), the $\left[{ }^{3} \mathrm{H}\right]$ DHD peak was identified and extracted from TLC plate silica and resuspended in ethanol.

Metabolism of the synthetic glucocorticoids DHD and DEX was investigated in stably transfected HEK293 cells overexpressing 11ßHSD2 (293T2). Briefly, cells were cultured in DMEM-high glucose supplemented with $10 \% \mathrm{FBS}$, pen/strep and $0.5 \mathrm{mg} / \mathrm{ml}$ geneticin (G418). Cells were treated with $100 \mathrm{nM}$ DHD or $100 \mathrm{nM}$ DEX with the equivalent tritiated tracers for $6 \mathrm{~h}$ for the assessment of enzyme activity. Similar experiments were carried out in the MG-63 OS cell line, which has previously been shown to have high levels of 11ß-HSD2 expression (Bland et al. 1999). All experiments were carried out in triplicate on three separate occasions. 


\section{Statistical analysis}

Pearson's product moment correlation coefficient was used to examine associations between continuous variables. Spearman's rank correlation coefficient was used to examine associations between noncontinuous variables (e.g. semiquantitative enzyme expression). A $P$ value of $<0.05$ was considered significant. All analyses were performed with SigmaStat Software (Systat Software, Inc., San Jose, CA, USA).

\section{Results}

\section{Expression of 11 $\beta$-HSD enzymes in pretreatment OS tissue}

Expression of $11 \beta$-HSD1 and $11 \beta$-HSD2 was determined in pretreatment biopsy tissue by immunohistochemistry. Both enzymes were detectable but each to a variable degree (Fig. 1A). In postchemotherapy samples, expression of both enzymes was also evident although again this was to varying degrees (Fig. 1B). Expression of 11 $\beta$-HSD enzyme protein by immunohistochemistry assessed semiquantitatively in a panel of OS biopsy specimens did not

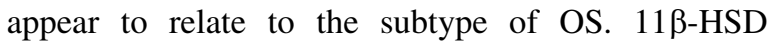
enzyme mRNA was also demonstrated in osteoblastomas (non-malignant bone tumours) but to a much lesser degree (Table 1).

The associations between pretreatment OS tissue enzyme expression, serum alkaline phosphatase activity and estimated primary tumour volume were examined. There was no association between $11 \beta$-HSD1 expression and alkaline phosphatase
(Fig. 2A). There was a trend towards an association of $11 \beta$-HSD2 expression and serum alkaline phosphatase $(r=0.57, P=0.06)$. $11 \beta$-HSD1 (but not 11ß-HSD2) expression was strongly associated with estimated primary tumour volume $(r=0.88$, $P<0.001)$.

\section{$11 \beta$-HSD enzymatic activity in post-chemotherapy resection specimens}

Owing to the limited amount of tissue available from the pretreatment biopsy specimens, enzyme activity and mRNA expression analysis were primarily carried out on post-chemotherapy resection specimens. Reductase activity (an activity exclusively mediated by the $11 \beta$-HSD1 enzyme) did not correlate with the level of necrosis (Fig. 3). Dehydrogenase activity (which could be mediated by either 11ß-HSD2 or $11 \beta$-HSD1) was, however, significantly associated with percentage of necrosis with low necrosis associated with high dehydrogenase activity. This association was also clearly evident when samples were analysed according to whether there was less than or more than $90 \%$ necrosis. To address the issue of the origin of the specific activities within the tissue, the

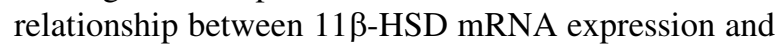
expression of alkaline phosphatase was explored. There was no correlation between 11ß-HSD1 and alkaline phosphatase mRNA expression. By contrast, there was a significant correlation between $11 \beta$-HSD2 and alkaline phosphatase mRNA expression. This indicated that the reductase activity was unlikely to be due to the residual OS tissue, but the dehydrogenase activity was due to $11 \beta-H S D 2$ expression within OS cells.
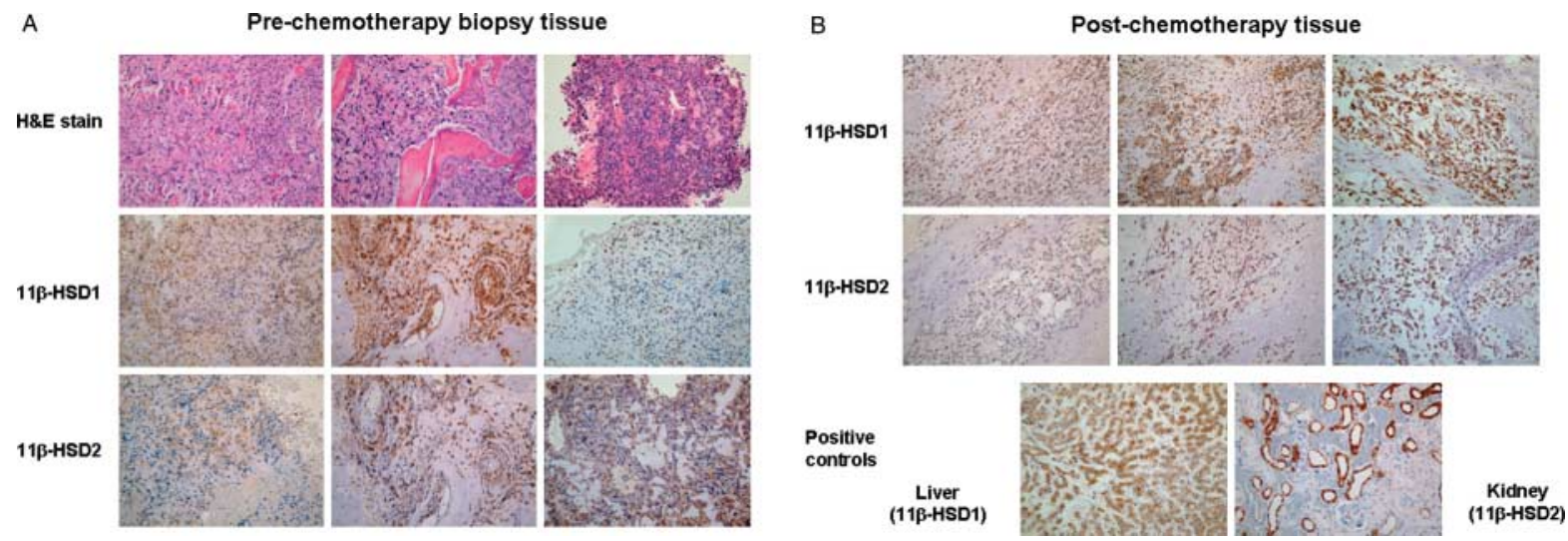

Figure $1 \mathrm{Immunohistochemical} \mathrm{analysis} \mathrm{of} 11 \beta$-HSD isozyme expression in human osteosarcoma tissue. Expression was examined in biopsy and resection specimens (A) before and (B) after chemotherapy. For each of three representative osteosarcoma samples staining for haematoxylin and eosin (H\&E), 11 $\beta$-HSD1 and 11 $\beta$-HSD2 expression is shown. Liver and kidney samples were used as positive controls for $11 \beta$-HSD1 and $11 \beta$-HSD2 expression respectively. 
Table 1 Semiquantitative analysis of glucocorticoid-modifying enzyme expression in malignant and non-malignant tumours arising from osteoblasts (pre-treatment biopsy specimens). Enzyme expression was assessed semiquantitatively in a blinded fashion on a scale of $0-4$, where 0 , indicated no expression; 1 , low expression; 2 , medium expression; 3 , high expression and 4 , very high expression

\begin{tabular}{|c|c|c|c|c|c|}
\hline Diagnosis & $\begin{array}{c}\text { Patient } \\
\text { age (years) }\end{array}$ & $\begin{array}{c}\text { Tumour } \\
\text { volume }\left(\mathrm{cm}^{3}\right)\end{array}$ & $\begin{array}{l}\text { Serum ALP at } \\
\text { diagnosis }(U / I)\end{array}$ & $\begin{array}{c}\text { 11 } \beta \text {-HSD1 } \\
\text { immunostaining } \\
(0-4 \text { scale })\end{array}$ & $\begin{array}{c}11 \beta \text {-HSD2 } \\
\text { immunostaining } \\
(0-4 \text { scale })\end{array}$ \\
\hline \multicolumn{6}{|l|}{ os } \\
\hline High-grade extraskeletal OS & 67 & 40.6 & 331 & 4 & 1 \\
\hline High-grade osteoblastic OS & 18 & 195 & 324 & 3 & 1 \\
\hline High-grade osteoblastic OS & 55 & ND & 1819 & 3 & 3 \\
\hline $\begin{array}{l}\text { High-grade osteoblastic and } \\
\text { focally chondroblastic } \\
\text { sarcoma }\end{array}$ & 10 & 367.5 & 601 & 2 & 2 \\
\hline High-grade osteoblastic OS & 21 & 101.2 & 308 & 2 & 2 \\
\hline High-grade osteoblastic OS & 13 & 351 & 253 & 3 & 1 \\
\hline High-grade osteoblastic OS & 19 & 252 & 183 & 3 & 1 \\
\hline High-grade osteoblastic OS & 12 & 731.2 & 2894 & 1 & 3 \\
\hline High-grade osteoblastic OS & 15 & 2112 & 709 & 0 & 1 \\
\hline High-grade osteoblastic OS & 15 & 36.75 & 266 & 4 & 1 \\
\hline High-grade osteoblastic OS & 4 & 57.7 & 851 & 4 & 1 \\
\hline \multicolumn{6}{|l|}{ Osteoblastoma } \\
\hline $\begin{array}{l}\text { Osteoblastoma with } \\
\text { epithelioid features }\end{array}$ & ND & ND & ND & NEG & NEG \\
\hline $\begin{array}{l}\text { Osteoblastoma with } \\
\text { pseudomalignant features }\end{array}$ & ND & ND & ND & 2 & 2 \\
\hline $\begin{array}{l}\text { Osteoblastoma with } \\
\text { pseudomalignant changes }\end{array}$ & ND & ND & ND & 2 & 1 \\
\hline Osteoblastoma & ND & ND & ND & NEG & NEG \\
\hline
\end{tabular}

ALP, alkaline phosphatase; NEG, negative; OS, osteosarcoma.

\section{Glucocorticoid metabolism in OS cells}

The metabolism of endogenous and synthetic glucocorticoids was examined in the MG-63 OS cell-line and the HEK293 cell-line transfected with 11ß-HSD2 (293T2). As expected, both cell-lines displayed exclusive dehydrogenase activity with the endogenous glucocorticoids, cortisol and cortisone (Fig. 4A and B). By contrast, the metabolism of DEX/DHD was bidirectional. In OS cells, the major enzymatic activity was reductase. In 293 T2 cells, the metabolism of DEX/DHD was clearly bidirectional with the dehydrogenase activity favoured. The $K_{\mathrm{m}}$ and $V_{\max }$ values for the dehydrogenase and reductase activities were in the nanomolar and micromolar ranges respectively (Fig. 4C). These studies confirm that OS cells have the capacity to generate active glucocorticoids from inactive precursors using selected synthetic glucocorticoids.

\section{Discussion}

Treatment options for OS are currently limited and the outcome after disease relapse after initial chemotherapy remains extremely poor. This study found that OS cells express the glucocorticoidmodifying enzymes, $11 \beta$-HSDs. Expression of both $11 \beta$-HSD1 and 11 -HSD2 enzymes was observed. Expression of the glucocorticoid-activating enzyme $11 \beta$-HSD1 in pretreatment specimens was strongly correlated with primary tumour volume, with low expression associated with greater tumour volume. $11 \beta$-HSD1 expression in post-treatment specimens did not correlate with response to chemotherapy, whereas high levels of the glucocorticoid-inactivating enzyme $11 \beta$-HSD2 in post-chemotherapy OS samples were associated with a poor response to chemotherapy. We have previously demonstrated that expression of the $11 \beta$-HSD2 enzyme is associated with a proproliferative action on pituitary tumour growth (Rabbitt et al. 2003). This raises the possibility that $11 \beta$-HSD2 expression and the corresponding reduced level of glucocorticoid exposure within the cell are an important determinant of OS aggressiveness. OS cells transfected with $11 \beta$-HSD1 proliferate more slowly than cells with low 11ß-HSD1 expression (Rabbitt et al. 2002). This could account for the observation 

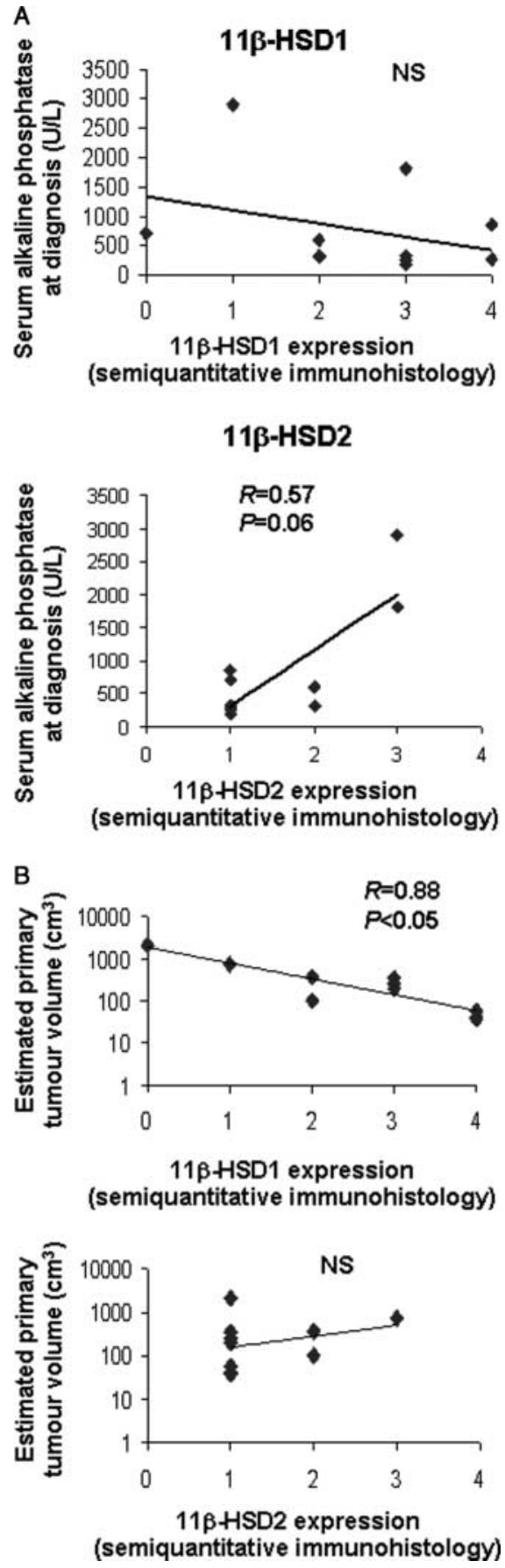

Figure 2 (A) Correlations between 11 $\beta$-HSD enzyme expression in pretreatment osteosarcoma tissue biopsies and serum alkaline phosphatase at diagnosis $(n=11)$. The expression of $11 \beta-$ HSD1 and $11 \beta-H S D 2$ were assessed semiquantitatively in a blinded fashion on a scale of $0-4$, where 0 , indicated no expression; 1 , low expression; 2 , medium expression; 3 , high expression and 4 , very high expression. (B) Correlations between $11 \beta-H S D$ enzyme expression in pretreatment osteosarcoma tissue biopsies and estimated primary tumour volume $(n=10)$. that high $11 \beta$-HSD1 expression in OS tissue in vivo is associated with smaller tumour volume.

The ability of $11 \beta-\mathrm{HSD} 2$ to inactivate endogenous glucocorticoids has been proposed as the mechanism by which $11 \beta$-HSD2 has a stimulatory effect on tumour proliferation (Rabbitt et al. 2002, 2003). An association of $11 \beta-H S D 2$ expression with malignancy or glucocorticoid resistance has also been reported in OS cells, pituitary tumours, adrenal tumours and leukaemic cells (Coulter et al. 1998, Rabbitt et al. 2002, 2003, Sai et al. 2011). Expression of 11 $\beta$-HSD2 in OS tissue will render it insensitive to endogenous glucocorticoids such as cortisol. The finding that OS 11ß-HSD2 enzyme expression could be used to activate, rather than inactivate, specific synthetic glucocorticoids suggests that any pro-tumour effect of $11 \beta$-HSD2 could be converted to an anti-tumour effect. The synthetic glucocorticoid chosen in this study has the advantage that its inactive form is generated to a small extent in vivo during treatment with DEX (Best et al. 1997). The lack of any harmful effects of this inactive glucocorticoid on healthy tissue makes it a good candidate to be taken forward for further study as a possible anti-cancer therapeutic. We therefore hypothesise that systemic treatment with DHD would have minimal effect on cells that lack $11 \beta$-HSD2, as DHD is unable to activate the glucocorticoid receptor. However, 11 $\beta$-HSD2 expression in OS tisuse would cause the intracellular generation of DEX from DHD. Some DEX would also be regenerated by endogenous $11 \beta$-HSD2 that is primarily found in the kidney. However, this is unlikely to be a problem as renal tubular cells do not appear to be detrimentally affected by DEX, and DEX is unable to bind to mineralocorticoid receptors and so would not cause hypertention (Cooper \& Stewart 1998). Although we have evaluated DHD, it is possible that structurally related synthetic glucocorticoids could be generated that have even greater ability to be activated powerfully and selectively by the $11 \beta$-HSD2 enzyme. Previous reports have analysed some of the structural determinants that determine directionality of glucocorticoid conversion by the $11 \beta-H S D$ enzymes (Diederich et al. 2002) and this should facilitate development of additional glucocorticoids.

An interesting observation within our study was the relative difference in the directionality of $11 \beta-\mathrm{HSD} 2$ for synthetic glucocorticoids between the MG-63 OS and transfected HEK cell line. The most likely explanation for this is the dependence of the $11 \beta$-HSD2 enzyme on the intracellular NADH/ $\mathrm{NAD}+$ ratio. $\mathrm{NADH}$ is an essential cofactor for the reductase reaction with synthetic glucocorticoids 

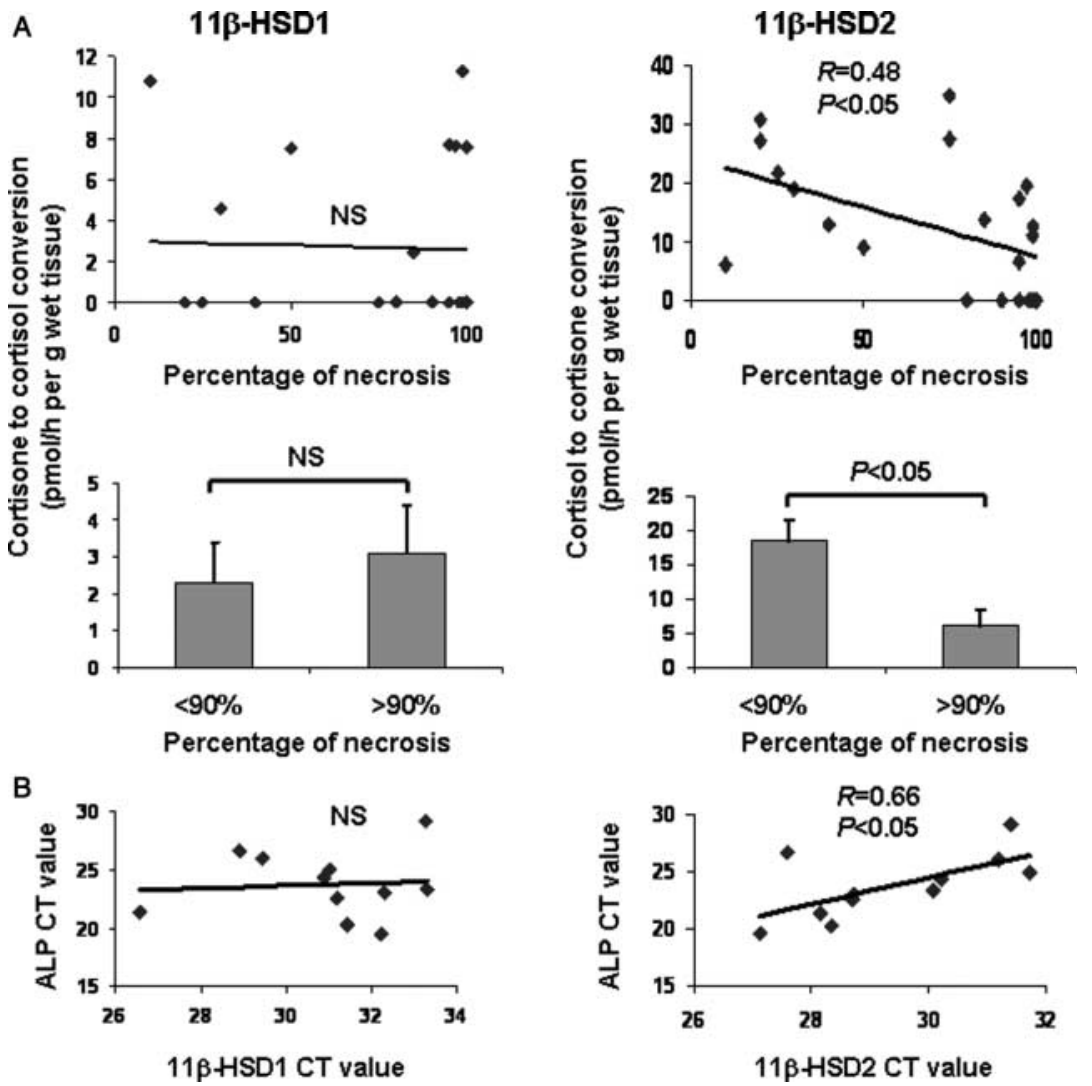

Figure 3 (A) Correlations between $11 \beta-H S D$ enzyme expression and response to chemotherapy. The mRNA expression and enzyme activity for $11 \beta-H S D 1$ and $11 \beta-H S D 2$ were assessed relative to the degree of necrosis measured in post-chemotherapy samples $(n=22)$. A level of necrosis of $<90 \%$ indicates a poor prognosis with osteosarcoma. (B) The correlation between mRNA expression for 11 $\beta$-HSD enzymes and alkaline phosphatase (a marker of osteoblasts/osteosarcoma tissue) was also examined $(n=11)$.

(Diederich et al. 2002). The NADH/NAD + ratio is known to be elevated in various cancers (Bui \& Thompson 2006) and the ratio is likely to be variable depending on the origin of the cell and the rapidity of its proliferation.

A limitation of our study is the problem of obtaining large amounts of OS tissue before chemotherapy. Pretreatment diagnosis of OS is typically based on the microscopic findings in needle biopsies, most of which has to be used for diagnostic purposes. As such, we were unable to examine quantitatively the relationship between $11 \beta$-HSD2 expression in pretreatment biopsies and the subsequent degree of tumour necrosis in response to chemotherapy. We were, however, able to perform a semiquantitative analysis of protein expression by immunohistochemistry and relate this to tumour characteristics known to have an impact on patient prognosis. This analysis demonstrated that both $11 \beta$-HSD1 and $11 \beta$-HSD2 were expressed but their expression was highly variable with variability greater for $11 \beta$-HSD1 than $11 \beta$-HSD2. Several factors are known to regulate $11 \beta-H S D 1$ expression in non-transformed osteoblasts. These include age, pro-inflammatory cytokines and glucocorticoids themselves (Cooper et al. 2001, 2002). In this small sample, $11 \beta$-HSD1 expression was not associated with age. It is possible that factors such as the local immune response could impact on $11 \beta-$ HSD 1 and therefore the rate of tumour proliferation, but this would need to be examined in further studies.

An issue potentially limiting the ability to use glucocorticoids such as DHD as an OS therapy is the almost universal use of high doses of DEX during chemotherapy. Although not part of the formal chemotherapy regimen, high doses of DEX are used for its anti-emetic properties. It will be interesting to examine the extent to which this use of DEX is related to beneficial responses to chemotherapy. Given the 
A

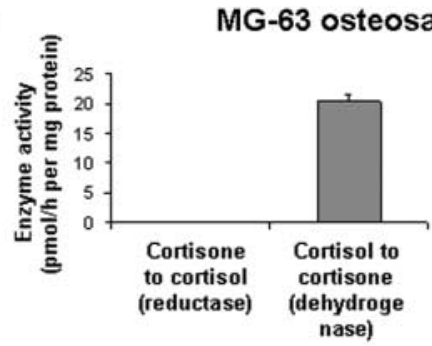

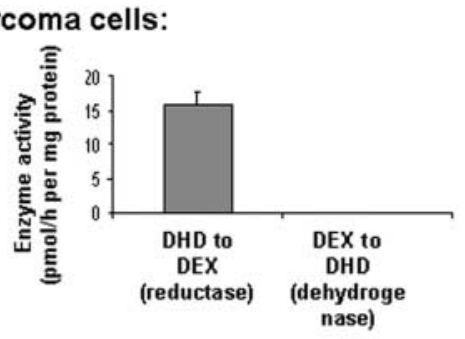

B

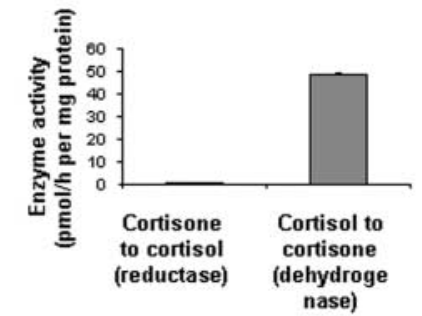

C

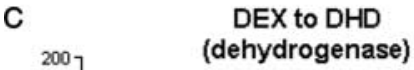

DEX to DHD

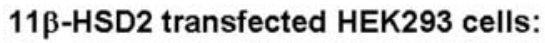
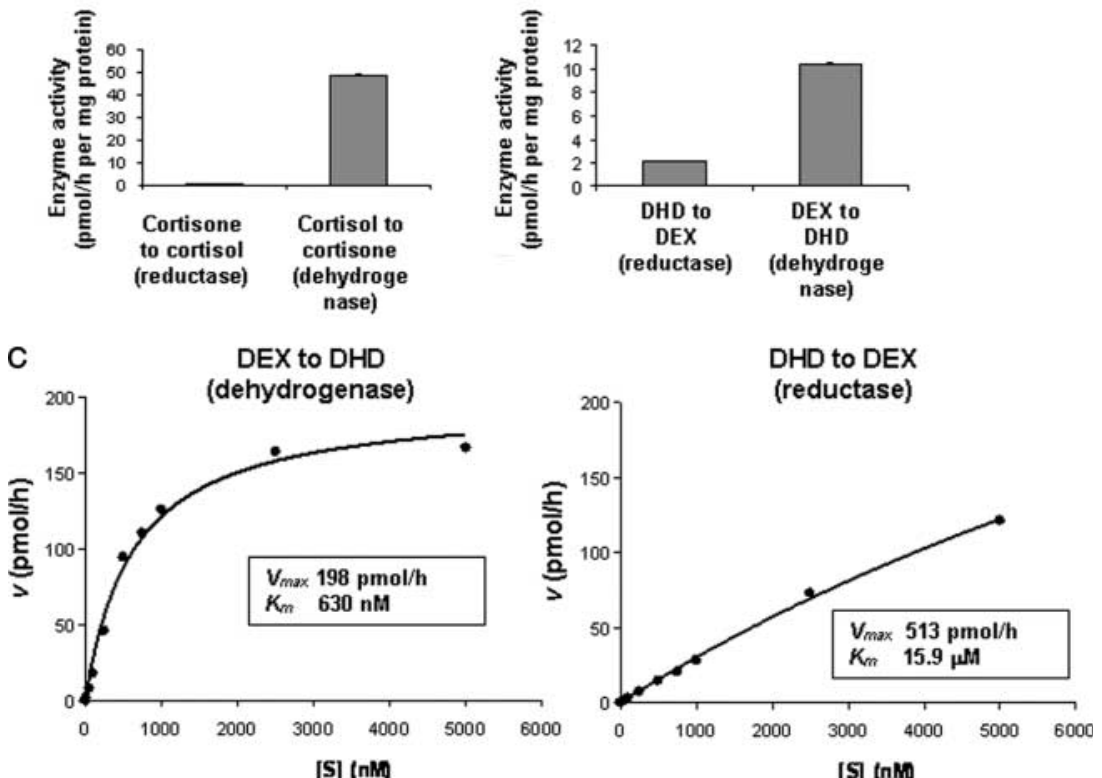

[S] (nM)

Figure 4 Enzymatic characterisation of metabolism of endogenous and synthetic glucocorticoids by osteosarcoma cells and cells

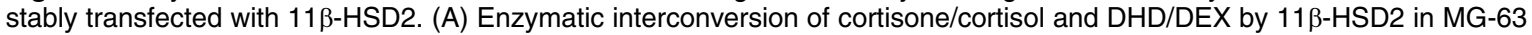
osteosarcoma cells. (B) Enzymatic interconversion of cortisone/cortisol and DHD/DEX by 11 $\beta$-HSD2 in transfected HEK293 cells. (C) Enzymatic characterisation of $11 \beta-H S D 2$ dehydrogenase and reductase reactions involving DHD/DEX. Experiments carried out in 11ß-HSD2-transfected HEK293 cells.

common use of glucocorticoids in the OS chemotherapy regimen, it is likely that inactive glucocorticoids will have most potential in treating patients with disease relapse. These patients have a poor prognosis using current treatment approaches and, as such, there is a need for novel therapeutic approaches in this setting.

We have demonstrated that OS tissue is capable of metabolising glucocorticoids and that $11 \beta$-HSD2-mediated glucocorticoid inactivation appears to be associated with tumour aggressiveness. However, glucocorticoids that lack biological activity in normal tissue can be selectively activated in OS tissue by the same enzyme. The development and use of glucocorticoids that are selectively activated by the $11 \beta$-HSD2 enzyme could form the basis of new therapies for OS.

\section{Declaration of interest}

The authors declare that there is no conflict of interest that could be perceived as prejudicing the impartiality of the research reported.

\section{Funding}

This study was funded by a grant from the University Hospital Birmingham Charities.

\section{Acknowledgements}

We would like to thank Maurice Adkins, Hamed Ali, Elaine Haywood and Karen Joynes from the Department of Musculoskeletal Pathology, Royal Orthopaedic Hospital, Birmingham for their technical assistance. 


\section{References}

Best R, Nelson SM \& Walker BR 1997 Dexamethasone and 11-dehydrodexamethasone as tools to investigate the isozymes of $11 \beta$-hydroxysteroid dehydrogenase in vitro and in vivo. Journal of Endocrinology 153 41-48. (doi:10.1677/joe.0.1530041)

Bland R, Worker CA, Noble BS, Eyre LJ, Bujalska IJ, Sheppard MC, Stewart PM \& Hewison M 1999 Characterization of $11 \beta$-hydroxysteroid dehydrogenase activity and corticosteroid receptor expression in human osteosarcoma cell lines. Journal of Endocrinology 161 455-464. (doi:10.1677/joe.0.1610455)

Bramer JA, Abudu AA, Tillman RM, Carter SR, Sumathi VP \& Grimer RJ 2005 Pre- and postchemotherapy alkaline phosphatase levels as prognostic indicators in adults with localised osteosarcoma. European Journal of Cancer 41 2846-2852. (doi:10.1016/j.ejca.2005.07.024)

Bui T \& Thompson CB 2006 Cancer's sweet tooth. Cancer Cell 9 419-420. (doi:10.1016/j.ccr.2006.05.012)

Cooper MS 2004 Sensitivity of bone to glucocorticoids. Clinical Science 107 111-123. (doi:10.1042/ CS20040070)

Cooper M \& Stewart PM 1998 The syndrome of apparent mineralocorticoid excess. Quarterly Journal of Medicine 91 453-455. (doi:10.1093/qjmed/91.7.453)

Cooper MS \& Stewart PM 2009 11 $\beta$-Hydroxysteroid dehydrogenase type 1 and its role in the hypothalamuspituitary-adrenal axis, metabolic syndrome, and inflammation. Journal of Clinical Endocrinology and Metabolism 94 4645-4654. (doi:10.1210/jc. 2009-1412)

Cooper MS, Walker EA, Bland R, Fraser WD, Hewison M \& Stewart PM 2000 Expression and functional consequences of $11 \beta$-hydroxysteroid dehydrogenase activity in human bone. Bone 27 375-381. (doi:10.1016/S8756-3282 (00)00344-6)

Cooper MS, Bujalska I, Rabbitt E, Walker EA, Bland R, Sheppard MC, Hewison M \& Stewart PM 2001 Modulation of $11 \beta$-hydroxysteroid dehydrogenase isozymes by proinflammatory cytokines in osteoblasts: an autocrine switch from glucocorticoid inactivation to activation. Journal of Bone and Mineral Research 16 1037-1044. (doi:10.1359/jbmr. 2001.16.6.1037)

Cooper MS, Rabbitt EH, Goddard PE, Bartlett WA, Hewison M \& Stewart PM 2002 Osteoblastic $11 \beta$-hydroxysteroid dehydrogenase type 1 activity increases with age and glucocorticoid exposure. Journal of Bone and Mineral Research 17 979-986. (doi:10.1359/jbmr.2002.17.6.979)

Coulter CL, Smith RE, Stowasser M, Sasano H, Krozowski ZS \& Gordon RD 1998 Expression of 11ßHSD-2 in human adrenal cortical carcinoma and adenoma. Endocrine Research 24 875-876. (doi:10.3109/ 07435809809032701)
Diederich S, Eigendorff E, Burkhardt P, Quinkler M, Bumke-Vogt C, Rochel M, Seidelmann D, Esperling P, Oelkers W \& Bahr V 2002 11ß-Hydroxysteroid dehydrogenase types 1 and 2: an important pharmacokinetic determinant for the activity of synthetic mine. Journal of Clinical Endocrinology and Metabolism 87 5695-5701. (doi:10.1210/jc.2002020970)

Eyre LJ, Rabbitt EH, Bland R, Hughes SV, Cooper MS, Sheppard MC, Stewart PM \& Hewison M 2001 Expression of $11 \beta$-hydroxysteroid dehydrogenase in rat osteoblastic cells: pre-receptor regulation of glucocorticoid responses in bone. Journal of Cellular Biochemistry 81 453-462. (doi:10.1002/1097-4644(20010601)81:3< 453::AID-JCB1059>3.0.CO;2-Z)

Hardy R, Rabbitt EH, Filer A, Emery P, Hewison M, Stewart PM, Gittoes NJ, Buckley CD, Raza K \& Cooper MS 2008 Local and systemic glucocorticoid metabolism in inflammatory arthritis. Annals of the Rheumatic Diseases 67 1204-1210. (doi:10.1136/ard. 2008.090662)

Kudawara I, Ueda T, Yoshikawa H, Miyama T, Yamamoto T \& Nishizawa Y 2001 In vivo inhibition of tumour growth by dexamethasone in murine osteosarcomas. European Journal of Cancer 37 1703-1708. (doi:10.1016/S09598049(01)00185-X)

Marina N, Gebhardt M, Teot L \& Gorlick R 2004 Biology and therapeutic advances for pediatric osteosarcoma. Oncologist 9 422-441. (doi:10.1634/ theoncologist.9-4-422)

O'Brien CA, Jia D, Plotkin LI, Bellido T, Powers CC, Stewart SA, Manolagas SC \& Weinstein RS 2004 Glucocorticoids act directly on osteoblasts and osteocytes to induce their apoptosis and reduce bone formation and strength. Endocrinology 145 1835-1841. (doi:10.1210/en. 2003-0990)

Rabbitt E, Lavery GG, Walker EA, Cooper MS, Stewart PM \& Hewison M 2002 Pre-receptor regulation of glucocorticoid action by $11 \beta$-hydroxysteroid dehydrogenase: a novel determinant of cell proliferation. FASEB Journal 16 36-44. (doi:10.1096/fj. 01-0582com)

Rabbitt EH, Ayuk J, Boelaert K, Sheppard MC, Hewison M, Stewart PM \& Gittoes NJ 2003 Abnormal expression of $11 \beta$-hydroxysteroid dehydrogenase type 2 in human pituitary adenomas: a prereceptor determinant of pituitary cell proliferation. Oncogene 22 1663-1667. (doi:10.1038/ sj.onc.1206293)

Raymond AK, Ayala AG \& Knuutila S 2002 Conventional osteosarcoma. In WHO Classification of Tumours. Tumours of Soft Tissue and Bone, pp 264-270. Eds, P Kleihues, L Sobin, C Fletcher et al. Lyon, France: IARC Press.

Sai S, Nakagawa Y, Yamaguchi R, Suzuki M, Sakaguchi K, Okada S, Seckl JR, Ohzeki T \& Chapman KE 2011 Expression of $11 \beta$-hydroxysteroid dehydrogenase 2 
contributes to glucocorticoid resistance in lymphoblastic leukemia cells. Leukemia Research 35 1644-1648. (doi:10.1016/j.leukres.2011.07.002)

Tomlinson JW, Walker EA, Bujalska IJ, Draper N, Lavery GG, Cooper MS, Hewison M \& Stewart PM $200411 \beta$-Hydroxysteroid dehydrogenase type 1: a tissuespecific regulator of glucocorticoid response. Endocrine Reviews 25 831-866. (doi:10.1210/er.2003-0031)
Wafa H \& Grimer RJ 2006 Surgical options and outcomes in bone sarcoma. Expert Review of Anticancer Therapy 6 239-248. (doi:10.1586/14737140.6.2.239)

Received in final form 3 June 2012 Accepted 19 June 2012

Made available online as an Accepted Preprint 20 June 2012 